\title{
Cardiovascular medication utilization and adherence among adults living in rural and urban areas: a systematic review and meta-analysis
}

\author{
Gaetanne K Murphy ${ }^{1}$, Finlay A McAlister ${ }^{2}$, Daniala L Weir ${ }^{1,3}$, Lisa Tjosvold ${ }^{3}$ and Dean T Eurich ${ }^{1,3^{*}}$
}

\begin{abstract}
Background: Rural residents face numerous barriers to healthcare access and studies suggest poorer health outcomes for rural patients. Therefore we undertook a systematic review to determine if cardiovascular medication utilization and adherence patterns differ for rural versus urban patients.

Methods: A comprehensive search of major electronic datasets was undertaken for controlled clinical trials and observational studies comparing utilization or adherence to cardiovascular medications in rural versus urban adults with cardiovascular disease or diabetes. Two reviewers independently identified citations, extracted data, and evaluated quality using the STROBE checklist. Risk estimates were abstracted and pooled where appropriate using random effects models. Methods and reporting were in accordance with MOOSE guidelines.

Results: Fifty-one studies were included of fair to good quality (median STROBE score 17.5). Although pooled unadjusted analyses suggested that patients in rural areas were less likely to receive evidence-based cardiovascular medications (23 studies, OR 0.88, 95\% Cl 0.79, 0.98), pooled data from 21 studies adjusted for potential confounders indicated no rural-urban differences (adjusted OR 1.02, 95\% Cl 0.91, 1.13). The high heterogeneity observed $\left(I^{2}=97 \%\right)$ was partially explained by treatment setting (hospital, ambulatory care, or community-based sample), age, and disease. Adherence did not differ between urban versus rural patients (3 studies, OR 0.94, 95\% Cl 0.39, 2.27, $I^{2}=91 \%$ ).

Conclusions: We found no consistent differences in rates of cardiovascular medication utilization or adherence among adults with cardiovascular disease or diabetes living in rural versus urban settings. Higher quality evidence is needed to determine if differences truly exist between urban and rural patients in the use of, and adherence to, evidence-based medications.
\end{abstract}

Keywords: Cardiovascular diseases, Rural population, Urban population, Medication adherence, Drug utilization

\section{Background}

Rural and urban communities have distinct characteristics in terms of demographics, social, and physical environments, and may vary in access to healthcare facilities and services. Rural residents tend to be older and are more likely to be obese, have less education, and lower income than urban residents [1-6]. Rural populations also have a higher prevalence of chronic conditions such as diabetes and heart disease [1,7-9]. Some studies have shown worse

\footnotetext{
* Correspondence: deurich@ualberta.ca

'2-040 Li Ka Shing Center for Health Research Innovation, School of Public

Health, University of Alberta, Edmonton, AB T6G 2E1, Canada

${ }^{3}$ Alliance for Canadian Health Outcomes Research in Diabetes, School of

Public Health, University of Alberta, Edmonton, Canada

Full list of author information is available at the end of the article
}

health outcomes among rural populations, including a higher risk of cardiovascular-related morbidity and mortality compared to urban populations [3,4,10-13]. For example, in Canada, mortality from circulatory diseases is higher in rural than urban communities, as is the risk of heart failure-related mortality, hospitalization and emergency department visits $[4,10,11]$. Similarly, in the UK a higher risk of in-hospital death due to ischemic heart disease has been observed among rural residents [12], and in Australia, mortality due to six major chronic diseases consistently increased in areas that were increasingly remote [13]. Collectively, these characteristics suggest increased healthcare needs for those living in rural communities. 
However, rural residents report several barriers to accessing healthcare including transportation difficulties and distance to care, social isolation, financial constraints, limited health care facilities (hospitals and pharmacies), physician shortages, and lack of access to specialist care [14-19]. Indeed, in the US, rural areas contain $19 \%$ of the population but only $11 \%$ of the physician workforce [15], and the ratio of specialists per population consistently declines as locations become smaller and more remote $[15,17]$. The lack of access to primary care physicians, specialists, or health care facilities has been postulated to result in decreased prescribing of evidence based medications. However, a previous systematic review found no clear rural-urban difference in the prevalence or intensity of prescription drug use in older adults - although that review included a wide variety of health conditions and medications [20]. It is possible that important differences may exist for certain disease states or medication conditions. As a result, we conducted a systematic review that evaluated whether cardiovascularrelated medication utilization and adherence patterns differ for rural versus urban adults with cardiovascular disease or diabetes. These two disease states were selected as they affect a large number of patients, are associated with high morbidity and mortality, often require multiple medications to manage, and outcomes are known to be different between rural and urban patients [21].

\section{Methods}

\section{Inclusion and exclusion criteria}

Controlled clinical trials or observational studies were included if they enrolled adults with established cardiovascular disease (atrial fibrillation, hypertension, heart failure, coronary artery disease) or diabetes, and reported cardiovascular medication use or adherence patterns for patients living in rural versus urban communities. Medications of interest included acetylsalicylic acid (ASA), antithrombotic, anticoagulant, antihypertensive (including angiotensin converting enzyme inhibitors (ACEI) and angiotensin receptor blockers (ARB)), or lipid lowering agents. The research question, inclusion and exclusion criteria, and review methods were outlined in a protocol developed a priori according to the PRISMA guidelines [22].

Since the definition of rural and urban varied substantially between studies, we a priori defined populations described as urban, city dwelling, or metropolitan in the primary publication as urban. Conversely, rural descriptors included town, village, country dwelling, nonmetropolitan or remote communities. Any definition of adherence or persistence used in primary studies was accepted. Only full text, peer reviewed articles, were included. Studies evaluating the use of medications for acute management, such as during hospitalization, were excluded, as were studies conducted in developing countries where management approaches may be substantially different. The populations of interest were those with established cardiovascular disease or diabetes, in whom several evidence-based medications are recommended for use. Two researchers (GKM, DLW) independently screened all studies and extracted all data using pre-defined forms and definitions, and disagreements were resolved through discussion, or by a third researcher (DTE).

\section{Literature search strategy}

A comprehensive search strategy implemented by a research librarian was done in April 2012 in the following electronic databases: MEDLINE ${ }^{\oplus}$ PubMed, Embase, International Pharmaceutical Abstracts, CINAHL, and Web of Science ${ }^{\oplus}$ and reference lists of included articles were also manually searched. Previously identified included studies were searched in Scopus to gather additional subject headings. No language, study design or date restrictions were applied. The MEDLINE ${ }^{\oplus}$ search strategy is listed in (Additional file 1: Table S1).

\section{Data extraction and quality assessment}

Studies were evaluated for bias, and the STROBE checklist was used to assess the quality of reporting [23]. Study authors were contacted for missing information on rural-urban comparisons, and in two cases additional data were provided (unpublished data V. Maio 2012, I. Carey 2011). Both unadjusted and adjusted data were abstracted or calculated where possible [24]. If more than one adjusted analysis was reported, the analysis that adjusted for the most confounders was extracted, and medication use data for patients without contraindications to treatment were preferred over populations that may have included patients who were not eligible for a specific therapy. Where possible, studies reporting multiple rural or urban populations were combined.

\section{Data analysis methods}

To summarize the effects of rural and urban location on medication utilization or adherence both unadjusted and adjusted pooled effects were calculated. As we expected heterogeneity between studies, we pooled effect estimates using a random effects model with inverse variance weighting and Review Manager 5.1 software [25]. Heterogeneity was assessed using the $\mathrm{I}^{2}$ statistic with an $\mathrm{I}^{2}$ statistic $>50 \%$ being considered as moderate heterogeneity. There was no a priori degree of heterogeneity that precluded pooling. For studies reporting multiple outcomes within the same cohort [e.g., \% receiving betablockers (BB) and \% receiving an ACEI], a pooled estimate of the odds of treatment were calculated using methods recommended by Borgenstein et al. [26] that accounts for the fact that patients within each outcome are not mutually exclusive (i.e., a patient may have received both a BB and an ACEI). Since the correlation of 
outcomes is unknown, we used a moderate correlation of 0.5 with sensitivity analyses using $0.25,0.75$ or 1 and found there was little impact on the results. Subgroup analyses were further conducted to explore the robustness of our results and potential sources of heterogeneity. Studies reporting data not suitable for meta-analysis (e.g. outcomes other than OR, or with missing data) were summarized narratively. Publication bias was assessed using funnel plots and Egger's test.

\section{Results}

A total of 11092 citations were identified in the literature search and 51 unique studies (described in 52 publications), met the inclusion criteria (Figure 1) [2,8,9,27-75]. Fifteen studies were cohort studies and 36 were cross sectional or repeat cross sectional studies (Additional file 1: Table S2). The included studies were published over a 21-year time span (1990 to 2011) and had quality scores based on the STROBE checklist that ranged from 8.5 to 21 (median 17.5) out of a total of 22 possible items (0.5 points given for partial reporting). Two reports provided

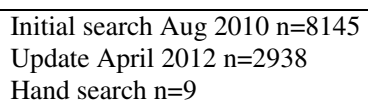

\section{Titles and abstracts reviewed: first round $(n=11092)$}

Excluded:

Duplicates $n=220$

Not relevant population $n=4649$

No medication use data $\mathrm{n}=1445$

Non-human or cellular studies $n=533$

Not relevant to research question $=1295$

Review articles, letters, abstracts, uncontrolled studies $n=1650$

\section{Titles and abstracts reviewed: second round $(n=1300)$}

\section{Excluded:}

Duplicates $n=3$

Not relevant population $n=397$

No medication use data $n=47$

Review articles, letters, abstracts, uncontrolled studies $n=32$ Other $\mathrm{n}=58$

\section{Complete articles reviewed $(n=763)$}

Excluded:

No rural urban comparison $n=520$

No cardiovascular medication use data $\mathrm{n}=32$

Wrong population $\mathrm{n}=58$

Wrong study design $n=36$

Abstract $\mathrm{n}=59$

Duplicate $\mathrm{n}=5$

Data included in another publication $\mathrm{n}=1$

\section{Articles included for review $\mathbf{n = 5 2}$ (51 unique studies)}

Studies included in meta-analyses: 36

Figure 1 Flow chart of systematic search. data on the same study $[44,48]$, and six studies included data for more than one patient cohort $[43,49,54,66,71,72]$. Thus, 58 patient populations (or cohorts) were included in our study. Two studies were in a language other than English and were translated using on-line resources and local expertise [37,70]. There was good agreement between reviewers on study selection (kappa 0.82 , 95\% confidence interval [CI] 0.75 to 0.90 ).

Patients were selected from a hospital setting in 12 studies, from ambulatory care practices in 17 studies, and in 22 studies, patients were selected from population-based or community-dwelling samples. Exploring rural-urban differences was the primary objective of 18 studies (35\%) $[2,27,28,30,31,35,36,39,43,44,49,51,54,59,68,69,71,73]$. Seven studies reported medication adherence (the proportion of doses taken as prescribed over a specific time period) or persistence (the length of continuous treatment) [76], and 47 reported outcomes related to medication utilization. Among the studies, there were substantial variations in how medication utilization or adherence to medications was assessed. Overall, 16 studies included patient selfreport, 31 studies included data from medical records or registries, and 5 studies were conducted using administrative databases. Nineteen studies reported crude utilization or adherence outcome data only $[8,28,35-37,39,40,50,51$, $53,54,63,64,67,68,71,73-75]$.

Included studies varied in their characteristics (Additional file 1: Table S2). Studies ranged in sample size from 32 to approximately one million and were conducted in a range of areas including the US (30 studies), Europe (14), Canada (5) and Australia (2). Patient populations included those with acute myocardial infarction or coronary artery disease (18 studies), hypertension (16), diabetes (8), chronic heart failure (6), atrial fibrillation (5), or mixed cardiovascular disease populations (5). The average age of study participants ranged from 42 to 80 years, and $28 \%$ to $63 \%$ were female.

\section{Medication utilization}

Forty seven (92\%) studies [2,8,9,27-36,38-47,49,51-69, 71-73,75] evaluated cardiovascular medication utilization with $20(39 \%)$ studies specifically evaluating utilization of ASA or other anti-thrombotic agents, 34 (67\%) evaluating antihypertensive use, and $11(22 \%)$ evaluating the use of lipid lowering agents (Additional file 1: Table S3). Substantial variation in the use of cardiovascular medications was observed between studies and between rural versus urban sub-populations within each study. Indeed, the absolute difference in the utilization of cardiovascular medications ranged from $-46 \%$ to $+4 \%$ in rural versus urban patients for ASA or other anti-thrombotic drugs, $-37 \%$ to $+25 \%$ for antihypertensive drugs, and $-45 \%$ to $+8 \%$ for lipid lowering agents. Of the 47 studies that evaluated cardiovascular medication use, sufficient data for pooling were available in 34 studies (39 separate 
cohorts as two cohorts were included in three studies $[43,66,72]$ and three cohorts in one study [71]). In the unadjusted pooled analyses (23 studies) [27-29,35,36,38,39, $41,43,44,46,47,51,53,55-58,64,68,71,73,75]$, patients in rural areas with cardiovascular disease or diabetes were less likely to receive evidence-based cardiovascular drug therapy compared to urban residents (pooled unadjusted OR $0.88,95 \%$ CI $0.79,0.98, \mathrm{p}=0.02 ; \mathrm{I}^{2}=97 \%$ ) (Table 1 ).
However, among the 21 studies that adjusted for potential confounders $[9,27,29,34,38,41-45,47,52,55,56,58,60-62,66$, $69,72]$ pooled analysis indicated no statistically significant difference between rural and urban patients in the use of cardiovascular medications (pooled adjusted OR 1.02, 95\% CI 0.91 to $1.13, \mathrm{p}=0.77, \mathrm{I}^{2}=97 \%$ ) (Figure 2). In both analyses there was substantial heterogeneity between studies. Although numerous subgroup analyses by setting, drug

Table 1 Meta-analysis of medication utilization and adherence outcomes

\begin{tabular}{|c|c|c|c|c|}
\hline Analysis & $\mathrm{N}$ cohorts* & $\begin{array}{l}\text { Rural/urban OR of } \\
\text { treatment }(95 \% \mathrm{Cl})\end{array}$ & $\mathrm{I}^{2}(\%)$ & $\begin{array}{l}\text { Subgroup } \\
\text { difference }\end{array}$ \\
\hline \multicolumn{5}{|l|}{ Cardiovascular medication utilization } \\
\hline Overall - unadjusted & 26 & $0.88(0.79,0.98)$ & 97 & NA \\
\hline Overall - adjusted & 23 & $1.02(0.91,1.13)$ & 97 & NA \\
\hline \multicolumn{5}{|l|}{ Subgroup analysis - adjusted } \\
\hline \multicolumn{5}{|l|}{ Setting } \\
\hline Community or population-based & 8 & $1.15(1.06,1.25)$ & 71 & $P<0.0001$ \\
\hline Hospital & 6 & $0.87(0.83,0.92)$ & 34 & \\
\hline Ambulatory care practice & 9 & $1.02(0.85,1.24)$ & 78 & \\
\hline \multicolumn{5}{|l|}{ Drug class } \\
\hline Antithrombotic or anticoagulant & 9 & $1.00(0.88,1.14)$ & 88 & $P=0.62$ \\
\hline Antihypertensive & 16 & $1.03(0.90,1.17)$ & 92 & \\
\hline Lipid lowering agent & 4 & $0.94(0.83,1.07)$ & 37 & \\
\hline \multicolumn{5}{|l|}{ Disease } \\
\hline Atrial fibrillation & 3 & $0.83(0.59,1.16)$ & 67 & $P=0.0001$ \\
\hline Cardiovascular disease & 11 & $0.95(0.88,1.03)$ & 67 & \\
\hline Hypertension & 6 & $1.07(0.87,1.33)$ & 79 & \\
\hline Diabetes & 3 & $1.21(1.12,1.31)$ & 76 & \\
\hline \multicolumn{5}{|l|}{ Age (study mean or median) } \\
\hline$<65$ years & 8 & $1.15(1.04,1.26)$ & 80 & $P=0.005$ \\
\hline$\geq 65$ years & 12 & $0.98(0.88,1.08)$ & 70 & \\
\hline Not reported & 3 & $0.89(0.77,1.02)$ & 64 & \\
\hline \multicolumn{5}{|l|}{ Country } \\
\hline US & 18 & $1.01(0.92,1.10)$ & 87 & $P=0.67$ \\
\hline Non-US & 5 & $1.05(0.88,1.26)$ & 88 & \\
\hline \multicolumn{5}{|l|}{ Publication Year } \\
\hline 1999-2005 & 7 & $1.06(0.91,1.22)$ & 76 & $P=0.66$ \\
\hline 2006-2011 & 16 & $1.01(0.88,1.15)$ & 98 & \\
\hline \multicolumn{5}{|l|}{ Data source } \\
\hline Administrative data & 2 & $1.17(0.97,1.41)$ & 87 & $P=0.19$ \\
\hline Medical record & 14 & $0.97(0.87,1.08)$ & 86 & \\
\hline Patient self-report & 7 & $1.07(0.93,1.22)$ & 72 & \\
\hline \multicolumn{5}{|c|}{ Cardiovascular medication adherence } \\
\hline & $\mathrm{N}$ & $\begin{array}{l}\text { Rural/urban OR of } \\
\text { treatment }(95 \% \mathrm{Cl})\end{array}$ & $I^{2}(\%)$ & $\begin{array}{l}\text { Subgroup } \\
\text { difference }\end{array}$ \\
\hline Overall - unadjusted & 4 & $0.94(0.39,2.27)$ & 91 & NA \\
\hline
\end{tabular}

*Data from 23 and 21 studies were included in the unadjusted and adjusted analyses, respectively: Ellis [43], Rice [66], Wan [71], and Williams [72] provided data for more than one cohort. $\mathrm{Cl}=$ confidence interval; $\mathrm{NA}=$ not applicable; $\mathrm{OR}=$ odds ratio. 
class, disease, age, country, and publication year were undertaken, similar results were observed and these factors only partially explained some of the variation between studies (Table 1; Figures 2 and 3). Moreover, when studies were categorized according to how the outcome was assessed (patient self-report, medical chart review, or administrative data), similar results were observed (Table 1). Additional analyses by study quality, for countries with universal health care systems, and for specific drugs, such as ACEI/ARB, also found similar findings (Additional file 1: Table S4). Among studies reporting data not suitable for meta-analysis, the findings were also consistent in that there was no clear trend towards a reduction or increase in cardiovascular medication utilization between rural and urban patients [2,8,30-33,40,49,54,59,63,65,67].

Publication bias was assessed by visually examining funnel plots and no obvious asymmetry was noted (Egger's $\mathrm{p}$ value $=0.98)$.

\section{Medication adherence or persistence}

Six (12\%) studies [29,37,46,70,73,74] evaluated cardiovascular medication adherence and two (4\%) studies $[46,50]$ evaluated medication persistence. Adherence was measured as the percentage of doses taken [73], the proportion of patients with a medication possession ratio $\geq 0.8$ [46], and was undefined in three studies $[37,70,74]$. Persistence was measured as the proportion of patients remaining on the same $[46,50]$ or any treatment [46] at the end of the follow up. In five studies, the drugs evaluated were antihypertensive agents, one study evaluated heart failure medications [73], and one assessed ASA or ACEI/ARB adherence [29].

Cardiovascular medication adherence or persistence findings were inconsistent across studies (Additional file 1: Table S3). The absolute difference in proportion adherent or persistent with medications ranged from $-41 \%$ to $+8 \%$ for rural versus urban patients. The odds of treatment persistence were significantly higher in rural versus urban patients in one report (adjusted OR 1.28, 95\% CI $1.25,1.32$ ) [46], but was not statistically different in a second study (OR 0.96, 95\% CI 0.55, 1.67) [50], Medication adherence data from three studies (4 cohorts) were pooled and showed no statistically significant difference between rural and urban patients (unadjusted OR 0.94, 95\% CI 0.39, 2.27, $\left.\mathrm{p}=0.89, \mathrm{I}^{2}=91 \%\right)$ Table $1[29,37,70]$. In two other reports with data not suitable for metaanalysis, medication adherence was significantly higher in one study ( $92 \%$ versus $83 \%$ of doses taken, $\mathrm{p}=0.01$ ) [73], and significantly lower in the other (10\% versus $17 \%$ of patients compliant, $\mathrm{p}<0.01$ ) [74], for rural versus urban 
patients, based on unadjusted data. The three studies reporting treatment adherence adjusted for confounders reported adherence to be significantly higher in rural patients (OR medication possession ratio $\geq 0.8$ : antihypertensive agents 1.2 , 95\% CI 1.1, 1.3; ASA 1.14, 95\% CI 1.10, 1.18; ACEI/ARB $1.1895 \%$ CI 1.14, 1.23) or rural men (OR adherent 4.0, 95\% CI 1.1, 13.9) $[29,46,70]$.

\section{Discussion}

Our systematic review of the literature found that rural patients were $12 \%$ less likely to receive cardiovascular medications than urban patients in unadjusted analyses; however, pooling of data adjusted for patient, practitioner or other factors revealed no differences in the proportions of rural and urban patients receiving therapy. This suggests that differences in these characteristics between rural and urban residents are largely responsible for the discrepancies in medication use observed and is consistent with previous studies showing important differences in the demographics, health behaviors, and overall health of people living in rural and urban areas $[1,3,4,7]$. In this review, many of the included reports provided little data on the demographics or comorbidities of the rural and urban patient groups, which hindered our ability to assess the similarity of these populations. As a result, it is difficult to draw conclusions from those studies that reported only unadjusted rural-urban comparisons.

When medication utilization data were pooled, substantial between-study heterogeneity was observed $\left(I^{2}=97 \%\right)$. Some of this variability could be explained by differences in the setting (hospital, ambulatory care practice or community-based sample), age, and disease state. While most studies adjusted for some clinical characteristics, only some controlled for socioeconomic factors that could also have impacted medication use. Indeed only fourteen studies $[27,32,34,42,43,45,47,52,57,58,61$, $62,66,69]$ reported adjustment for health insurance and previous studies have shown patients with a chronic condition who lack medication insurance are less likely to take medications or frequently skip doses due to cost [52,66,77].

Similarly, we found no consistent relationship between rural residence and cardiovascular medication adherence 
or persistence rates based on unadjusted data. The adjusted analysis suggested higher adherence and persistence for rural residents, although there were few studies reporting these outcomes. Rural-urban differences in other health behaviors, such as smoking, exercise, and consumption of fruits and vegetables have been reported [4], and considering the link between adherence and positive health outcomes [78], further study is warranted.

Although we conducted an exhaustive search for literature and conducted our systematic review in accordance to the highest reporting standards, our review is not without limitations. Firstly, studies evaluating differences in urban versus rural settings within subgroup analyses may not have been easily identified. Second, as in any systematic review, the findings are limited by the quality of the individual studies. Potential limitations included reporting bias [32, $33,40,41,45,49,51,54,71,72]$, selection bias $[9,35,54]$, lack of generalizability $[9,28,36,37,39,50,51,59,71,73,74]$, limited sample size $[28,36,37,39,50,64,73]$, no adjustment for confounders $[8,28,35-37,40,50,54,64,74,75]$, and poor reporting (STROBE score below the 25th percentile) $[8,28,36,37,40,44,50-52,54,59,64,70,71,74]$. Third, we accepted a broad range of definitions for rural and urban populations, which may have affected study results. In 25 studies [8,28,34,36,37,40-43,45,46,50,52,53,55-60, 64-66,72,74] no clear definition of rural and urban were provided and various definitions were used in the remaining studies. It is possible some of the heterogeneity observed in our pooled analysis is related to these differences in definitions, although subgroup analysis by studies with defined and undefined rural populations showed similar results. Fourth, between-study heterogeneity was high and not fully explained despite multiple subgroup analyses by setting, drug class, disease, age, country, publication year, and data source (self-report, administrative or medical records). Moreover, clinical indications and classification of disease may also have changed over time increasing the heterogeneity between studies. Last, our review only included adults with established cardiovascular disease as medication utilization for secondary prevention was expected to be high within patients; thus, improving the power to detect differences if differences exist between rural and urban patients. Moreover, as cardiovascular medications are widely prescribed medications in the general adult population, our results would be expected to be highly generalizable.

\section{Conclusions}

In conclusion, we found no consistent relationship between rural versus urban residence and utilization of, or adherence with evidence-based cardiovascular medications among adults with cardiovascular disease or diabetes. There was substantial between-study variation that was only partially explained by the setting, age, and disease. Higher quality evidence is needed to determine if differences in cardiovascular medication utilization and adherence between urban and rural patients truly exist.

\section{Additional file}

Additional file 1: The supplementary material includes Tables S1-S4, the literature search strategy, summary of the included study

characteristics and results, and the supplementary meta-analyses.

Competing interests

The authors declare that they have no competing interests.

\section{Authors' contributions}

GKM and DLW screened, extracted and assessed the quality of studies. GKM conducted the meta-analysis. LT conducted the literature search and prepared the bibliography. GKM, DTE and FAM drafted the report. All authors had full access to all of the data (including statistical reports and tables) in the study and can take responsibility for the integrity of the data and accuracy of the data analysis. All authors read and approved the final manuscript.

\section{Author details}

${ }^{1}$ 2-040 Li Ka Shing Center for Health Research Innovation, School of Public Health, University of Alberta, Edmonton, AB T6G 2E1, Canada. ${ }^{2}$ Division of General Internal Medicine, Department of Medicine, Medicine and Dentistry, University of Alberta, Edmonton, Canada. ${ }^{3}$ Alliance for Canadian Health Outcomes Research in Diabetes, School of Public Health, University of Alberta, Edmonton, Canada.

Received: 20 November 2013 Accepted: 27 May 2014

Published: 2 June 2014

\section{References}

1. Krishna S, Gillespie KN, McBride TM: Diabetes burden and access to preventive care in the rural United States. J Rural Health 2010, 26:3-11.

2. Vanasse A, Courteau J, Cohen AA, Orzanco MG, Drouin C: Rural-urban disparities in the management and health issues of chronic diseases in Quebec (Canada) in the early 2000s. Rural Remote Health 2010, 10:1548.

3. Probst JC, Bellinger JD, Walsemann KM, Hardin J, Glover SH: Higher risk of death in rural blacks and whites than urbanites is related to lower incomes, education, and health coverage. Health Aff (Millwood) 2011, 30:1872-1879.

4. DesMeules M, Pong R, Lagace C, Heng D, Manuel D, Pitblado R, Bollman R, Guernsey J, Kazanjian A, Koren I: How Healthy Are Rural Canadians: An Assessment Of Their Health Status And Health Determinants. Ottawa, ON: Canadian Institute for Health Information; 2006: https://secure.cihi.ca/ free_products/acknowledgements_rural_canadians_2006_report_e.pdf. Accessed 2012 Sep 01.

5. Gartner A, Farewell D, Roach P, Dunstan F: Rural/urban mortality differences in England and Wales and the effect of deprivation adjustment. Soc Sci Med 2011, 72:1685-1694.

6. Smith KB, Humphreys JS, Wilson MGA: Addressing the health disadvantage of rural populations: how does epidemiological evidence inform rural health policies and research? Aust J Rural Health 2008, 16:56-66.

7. Jones A, Goza F: Rural, suburban and urban differences in the self-diagnosis of coronary heart disease in the United States. J Biosoc Sci 2008, 40:895-909.

8. Banegas JR, Rodriguez-Artalejo F, de la Cruz Troca JJ, Guallar-Castillon P, del Rey Calero J: Blood pressure in Spain: distribution, awareness, control, and benefits of a reduction in average pressure. Hypertension 1998, 32:998-1002.

9. Psaltopoulou T, Orfanos P, Naska A, Lenas D, Trichopoulos D, Trichopoulou A: Prevalence, awareness, treatment and control of hypertension in a general population sample of 26,913 adults in the Greek EPIC study. Int J Epidemiol 2004, 33:1345-1352.

10. Gamble JM, Eurich DT, Ezekowitz JA, Kaul P, Quan H, McAlister FA: Patterns of care and outcomes differ for urban versus rural patients with newly diagnosed heart failure, even in a universal healthcare system. Circ Heart Fail 2011, 4:317-323. 
11. Teng T-HK, Katzenellenbogen JM, Hung J, Knuiman M, Sanfilippo FM, Geelhoed E, Hobbs M, Thompson SC: Rural-urban differentials in 30-day and 1-year mortality following first-ever heart failure hospitalisation in Western Australia: a population-based study using data linkage. BMJ Open 2014, 4:e004724

12. Levin $\mathrm{KA}$, Leyland $\mathrm{AH}$ : Urban-rural inequalities in ischemic heart disease in Scotland, 1981-1999. Am J Public Health 2006, 96:145-151.

13. Chondur R, Li SQ, Guthridge S, Lawton P: Does relative remoteness affect chronic disease outcomes? Geographic variation in chronic disease mortality in Australia, 2002-2006. Aust N Z J Public Health 2014, 38:117-121.

14. Goins RT, Williams KA, Carter MW, Spencer SM, Solovieva T: Perceived barriers to health care access among rural older adults: a qualitative study. J Rural Health 2005, 21:206-213.

15. Fordyce MA, Chen FM, Doescher MP, Hart LG: 2005 Physician Supply and Distribution in Rural Areas of the United States. Final Report. WWAMI Rural Health Research Center, University of Washington; 2007: Report No: 116. http://depts.washington.edu/uwrhrc/uploads/RHRC\%20FR116\%20Fordyce.pdf.

16. Aneja S, Ross JS, Wang Y, Matsumoto M, Rodgers GP, Bernheim SM, Rathore SS, Krumholz HM: US cardiologist workforce from 1995 to 2007: modest growth, lasting geographic maldistribution especially in rural areas. Health Aff (Millwood) 2011, 30:2301-2309.

17. Pong RW, DesMeules M, Heng D, Lagace C, Guernsey JR, Kazanjian A, Manuel D, Pitblado JR, Bollman R, Koren I, Dressler MP, Wang F, Luo W: Patterns of health service utilization in rural Canada. Chronic Dis Can 2011, 31(Supp 1):1-36

18. Sibley LM, Weiner JP: An evaluation of access to health care services along the rural-urban continuum in Canada. BMC Health Serv Res 2011, 11:20.

19. Klepser DG, Xu L, Ullrich F, Mueller KJ: Trends in community pharmacy counts and closures before and after the implementation of Medicare part D. J Rural Health 2011, 27:168-175.

20. Grymonpre RE, Hawranik PG: Rural residence and prescription medication use by community-dwelling older adults: a review of the literature. J Rural Health 2008, 24:203-209.

21. Roger VL, Go AS, Lloyd-Jones DM, Benjamin EJ, Berry JD, Borden WB, Bravata DM, Dai S, Ford ES, Fox CS, Fullerton HJ, Gillespie C, Hailpern SM, Heit JA Howard VJ, Kissela BM, Kittner SJ, Lackland DT, Lichtman JH, Lisabeth LD, Makuc DM, Marcus GM, Marelli A, Matchar DB, Moy CS, Mozaffarian D, Mussolino ME, Nichol G, Paynter NP, Soliman EZ: Heart disease and stroke statistics-2012 update: a report from the American heart association. Circulation 2012, 125:e2-e220.

22. Moher D, Liberati A, Tetzlaff J, Altman DG: Preferred reporting items for systematic reviews and meta-analyses: the PRISMA statement. PLoS Med 2009, 6:e1000097.

23. von Elm E, Altman DG, Egger M, Pocock SJ, Gotzsche PC, Vandenbroucke JP: Strengthening the reporting of observational studies in epidemiology (STROBE) statement: guidelines for reporting observational studies. J Clin Epidemiol 2008, 61:344-349.

24. Altman DG, Bland JM: How to obtain the confidence interval from a P value. BMJ 2011, 343:d2090.

25. Review Manager (RevMan). [Computer program]. Version 5.1: Review Manager (RevMan). [Computer program]. Version 5.1. Copenhagen: The Nordic Cochrane Centre, The Cochrane Collaboration; 2011.

26. Borgenstein M, Hedges LV, Higgins JPT, Rothstein HR: Multiple outcomes or time-points within a study. In Introduction to Meta-Analysis. Chichester, UK: John Wiley \& Sons; 2009:225-238

27. Ambardekar AV, Fonarow GC, Dai D, Peterson ED, Hernandez AF, Cannon CP, Krantz MJ: Quality of care and in-hospital outcomes in patients with coronary heart disease in rural and urban hospitals (from get with the guidelines-coronary artery disease program). Am J Cardiol 2010, 105:139-143.

28. Andrus MR, Kelley KW, Murphey LM, Herndon KC: A comparison of diabetes care in rural and urban medical clinics in Alabama. J Community Health 2004, 29:29-44.

29. Asghari S, Courteau J, Drouin C, Gregoire JP, Carpentier AC, Paquet M, Vanasse A: Adherence to vascular protection drugs in diabetic patients in Quebec: a population-based analysis. Diab Vasc Dis Res 2010, 7:167-171.

30. Baldwin LM, Chan L, Andrilla CH, Huff ED, Hart LG: Quality of care for myocardial infarction in rural and urban hospitals. J Rural Health 2010, 26:51-57.

31. Baldwin LM, MacLehose RF, Hart LG, Beaver SK, Every N, Chan L: Quality of care for acute myocardial infarction in rural and urban US hospitals. J Rural Health 2004, 20:99-108.
32. Bradley EH, Herrin J, Mattera JA, Holmboe ES, Wang Y, Frederick P, Roumanis SA, Radford MJ, Krumholz HM: Hospital-level performance improvement: beta-blocker use after acute myocardial infarction. Med Care 2004, 42:591-599.

33. Bradley EH, Herrin J, Mattera JA, Holmboe ES, Wang Y, Frederick $P$, Roumanis SA, Radford MJ, Krumholz HM: Quality improvement efforts and hospital performance: rates of beta-blocker prescription after acute myocardial infarction. Med Care 2005, 43:282-292.

34. Byrne M, Murphy AW, Walsh JC, Shryane E, McGroarty M, Kelleher CC: A cross-sectional study of secondary cardiac care in general practice: impact of personal and practice characteristics. Fam Pract 2006, 23:295-302.

35. Clark RA, Eckert KA, Stewart S, Phillips SM, Yallop JJ, Tonkin AM, Krum H: Rural and urban differentials in primary care management of chronic heart failure: new data from the CASE study. Med J Aust 2007, 186:441-445.

36. Colleran KM, Richards A, Shafer K: Disparities in cardiovascular disease risk and treatment: demographic comparison. J Investig Med 2007, 55:415-422.

37. Czarnecka D, Pawelec M, Kopacz E, Kloch M: Socioeconomical status of life and regularity of intake of medicines among hypertensive patients. Przegl Lek 2006, 63:633-636.

38. de Oliveira-Martins S, Oliveira T, Gomes JJF, Caramona M, Cabrita J: Factors associated with arterial hypertension in pharmacy users in Portugal. Rev Saude Publica 2011, 45:136-144

39. Dellasega C, Orwig D, Ahern F, Lenz E: Postdischarge medication use of elderly cardiac patients from urban and rural locations. J Gerontol A Biol Sci Med Sci 1999, 54:M514-M520.

40. DeWilde S, Carey IM, Bremner SA, Richards N, Hilton SR, Cook DG: Evolution of statin prescribing 1994-2001: a case of agism but not of sexism? Heart 2003, 89:417-421.

41. DeWilde S, Carey IM, Emmas C, Richards N, Cook DG: Trends in the prevalence of diagnosed atrial fibrillation, its treatment with anticoagulation and predictors of such treatment in UK primary care. Heart 2006, 92:1064-1070.

42. DiMartino LD, Shea AM, Hernandez AF, Curtis LH: Use of guidelinerecommended therapies for heart failure in the medicare population. Clin Cardiol 2010, 33:400-405.

43. Ellis $C$, Grubaugh AL, Egede LE: The effect of minority status and rural residence on actions to control high blood pressure in the U.S. Public Health Rep 2010, 125:801-809.

44. Flaker GC, McGowan DJ, Boechler M, Fortune G, Gage B: Underutilization of antithrombotic therapy in elderly rural patients with atrial fibrillation. Am Heart J 1999, 137:307-312.

45. Fonarow GC, French WJ, Frederick PD: Trends in the use of lipid-lowering medications at discharge in patients with acute myocardial infarction: 1998 to 2006. Am Heart J 2009, 157:185-194.

46. Friedman O, McAlister FA, Yun L, Campbell NR, Tu K: Antihypertensive drug persistence and compliance among newly treated elderly hypertensives in Ontario. Am J Med 2010, 123:173-181.

47. Funkhouser E, Houston TK, Levine DA, Richman J, Allison JJ, Kiefe Cl: Physician and patient influences on provider performance: beta-blockers in postmyocardial infarction management in the Ml-Plus study. Circ Cardiovasc Qual Outcomes 2011, 4:99-106.

48. Gage BF, Boechler M, Doggette AL, Fortune G, Flaker GC, Rich MW, Radford MJ: Adverse outcomes and predictors of underuse of antithrombotic therapy in medicare beneficiaries with chronic atrial fibrillation. Stroke 2000, 31:822-827.

49. Goldman LE, Dudley RA: United States rural hospital quality in the hospital compare database-accounting for hospital characteristics. Health Policy 2008, 87:112-127.

50. Hense HW, Tennis P: Changing patterns of antihypertensive drug use in a German population between 1984 and 1987. Results of a population based cohort study in the federal republic of Germany. Eur J Clin Pharmacol 1990, 39:1-7.

51. Hicks PC, Bublitz Emsermann C, Westfall JM, Parnes B: Comparison of HTN management in patients with diabetes between rural and urban primary care clinics in Northeastern Colorado - a report from SNOCAP. Rural Remote Health 2010, 10:1-11.

52. Huttin C: The role of different types of health insurance on access and utilization of antihypertensive drugs: an empirical study in a US hypertensive population. Dis Manag Health Outcome 2002, 10:419-430.

53. Ko DT, Mamdani M, Alter DA: Lipid-lowering therapy with statins in high-risk elderly patients: the treatment-risk paradox. JAMA 2004, 291:1864-1870. 
54. Lutfiyya MN, Bhat DK, Gandhi SR, Nguyen C, Weidenbacher-Hoper VL, Lipsky MS: A comparison of quality of care indicators in urban acute care hospitals and rural critical access hospitals in the United States. Int J Qual Health Care 2007, 19:141-149.

55. Ma J, Stafford RS: Screening, treatment, and control of hypertension in US private physician offices, 2003-2004. Hypertension 2008, 51:1275-1281.

56. Maio V, Marino M, Robeson M, Gagne JJ: Beta-blocker initiation and adherence after hospitalization for acute myocardial infarction. Eur J Cardiovasc Prev Rehabil 2011, 18:438-445.

57. Majumdar SR, Gurwitz JH, Soumerai SB: Undertreatment of hyperlipidemia in the secondary prevention of coronary artery disease. J Gen Intern Med 1999, 14:711-717.

58. Majumdar SR, Inui TS, Gurwitz JH, Gillman MW, McLaughlin TJ, Soumerai SB: Influence of physician specialty on adoption and relinquishment of calcium channel blockers and other treatments for myocardial infarction. J Gen Intern Med 2001, 16:351-359.

59. Munschauer FE, Priore RL, Hens M, Castilone A: Thromboembolism prophylaxis in chronic atrial fibrillation: practice patterns in community and tertiary-care hospitals. Stroke 1997, 28:72-76.

60. Nguyen KX, Marinac JS, Sun C: Aspirin for primary prevention in patients with diabetes mellitus. Fam Med 2005, 37:112-117.

61. Niska R, Han B: Statins for secondary cardiovascular disease prevention for older primary care patients. J Natl Med Assoc 2009, 101:705-710.

62. Niska R, Han B: Anticoagulation for patients with atrial fibrillation in ambulatory care settings. J Am Board Fam Med 2009, 22:299-306.

63. Obisesan TO, Vargas CM, Gillum RF: Geographic variation in stroke risk in the United States - region, urbanization, and hypertension in the third national health and nutrition examination survey. Stroke 2000, 31:19-25.

64. Perez-Fernandez R, Marino AF, Cadarso-Suarez C, Botana MA, Tome MA, Solache I, Rego-Iraeta A, Mato AJ: Prevalence, awareness, treatment and control of hypertension in Galicia (Spain) and association with related diseases. J Hum Hypertens 2007, 21:366-373.

65. Pittrow D, Kirch W, Bramlage P, Lehnert H, Hofler M, Unger T, Sharma AM, Wittchen HU: Patterns of antihypertensive drug utilization in primary care. Eur J Clin Pharmacol 2004, 60:135-142.

66. Rice T, Lavarreda SA, Ponce NA, Brown ER: The impact of private and public health insurance on medication use for adults with chronic diseases. Med Care Res Rev 2005, 62:231-249.

67. Rowan SB, Bailey DN, Bublitz CE, Anderson RJ: Trends in anticoagulation for atrial fibrillation in the U.S.: an analysis of the national ambulatory medical care survey database. J Am Coll Cardiol 2007, 49:1561-1565.

68. Sheikh K, Bullock C: Urban-rural differences in the quality of care for medicare patients with acute myocardial infarction. Arch Intern Med 2001, 161:737-743.

69. Strom $J$, Lynch CP, Egede LE: Rural/urban variations in diabetes self-care and quality of care in a national sample of US adults with diabetes. Diabetes Educ 2011, 37:254-262.

70. Tuesca-Molina R, Guallar-Castillon P, Banegas-Banegas JR, Graciani-Perez Regadera A: Determinants of the adherence to therapeutic plan in elderly Spaniards, over 60 years of age. Gac Sanit 2006, 20:220-227.

71. Wan Q, Harris MF, Davies GP, Jayasinghe UW, Flack J, Georgiou A, Burns JR, Penn DL: Cardiovascular risk management and its impact in Australian general practice patients with type 2 diabetes in urban and rural areas. Int J Clin Pract 2008, 62:53-58.

72. Williams SC, Koss RG, Morton DJ, Schmaltz SP, Loeb JM: Case volume and hospital compliance with evidence-based processes of care. Int J Qual Health Care 2008, 20:79-87.

73. Wu JR, Moser DK, Rayens MK, De Jong MJ, Chung ML, Riegel B, Lennie TA: Rurality and event-free survival in patients with heart failure. Heart Lung 2010, 39:512-520.

74. Yiannakopoulou EC, Papadopulos JS, Cokkinos DV, Mountokalakis TD: Adherence to antihypertensive treatment: a critical factor for blood pressure control. Eur J Cardiovasc Prev Rehabil 2005, 12:243-249.

75. Yusuf S, Islam S, Chow CK, Rangarajan S, Dagenais G, Diaz R, Gupta R, Kelishadi R, lqbal R, Avezum A, Kruger A, Kutty R, Lanas F, Lisheng L, Wei L, Lopez-Jaramillo P, Oguz A, Rahman O, Swidan H, Yusoff K, Zatonski W, Rosengren A, Teo KK: Use of secondary prevention drugs for cardiovascular disease in the community in high-income, middle-income, and low-income countries (the PURE Study): a prospective epidemiological survey.

Lancet 2011, 378:1231-1243.
76. Cramer JA, Roy A, Burrell A, Fairchild CJ, Fuldeore MJ, Ollendorf DA, Wong PK: Medication compliance and persistence: terminology and definitions. Value Health 2008, 11:44-47.

77. Kwan J, Razzaq A, Leiter LA, Lillie D, Hux JE: Low socioeconomic status and absence of supplemental health insurance as barriers to diabetes care access and utilization. Can J Diabetes 2008, 32:174-181.

78. Simpson SH, Eurich DT, Majumdar SR, Padwal RS, Tsuyuki RT, Varney J, Johnson JA: A meta-analysis of the association between adherence to drug therapy and mortality. BMJ 2006, 333:15.

doi:10.1186/1471-2458-14-544

Cite this article as: Murphy et al.: Cardiovascular medication utilization and adherence among adults living in rural and urban areas: a systematic review and meta-analysis. BMC Public Health 2014 14:544.

\section{Submit your next manuscript to BioMed Central and take full advantage of:}

- Convenient online submission

- Thorough peer review

- No space constraints or color figure charges

- Immediate publication on acceptance

- Inclusion in PubMed, CAS, Scopus and Google Scholar

- Research which is freely available for redistribution

Submit your manuscript at www.biomedcentral.com/submit
C) Biomed Central 